\title{
Paisagens vividas, trabalhadas, truncadas: iconografia da periferia urbana no Cinema Ibérico da Austeridade ${ }^{1}$
}

\author{
Iván Villarmea Álvarez ${ }^{2}$
}

\footnotetext{
${ }^{1}$ Este texto é uma versão estendida de uma comunicação homônima apresentada na Faculdade de Letras da Universidade de Lisboa durante a International Conference on Landscape and Cinema (3 a 5 de dezembro de 2018).

2 Doutor em História da Arte pela Universidade de Zaragoza e investigador de pós-doutoramento na Universidade de Santiago de Compostela. Autor do livro Documenting cityscapes. urban change in contemporary non-fiction film (2015) e coeditor dos volumes Jugar con la memoria: el cine portugués en el siglo XXI (2014, com Horacio Muñoz Fernández) e New approaches to cinematic space (2019, com Filipa Rosário). Este artigo é resultado do seu projeto de pesquisa "As paisagens da crise. A representação da grande recessão nos cinemas ibéricos (2008-2018)". email: ivillarmea@gmail.com
} 


\section{Resumo}

Este artigo tenciona analisar a presença recorrente de dois elementos iconográficos ligados à Grande Recessão (2008-2014) nas representações cinematográficas das periferias urbanas ibéricas. Estes dois elementos são as fábricas fechadas e as obras abandonadas, dois signos da crise recente no setor industrial e na construção civil que têm aparecido em muitos filmes do cinema ibérico da austeridade, como Cavalo Dinheiro (Pedro Costa, 2014), As mil e uma noites (Miguel Gomes, 2015), São Jorge (Marco Martins, 2016) e A fábrica de nada (Pedro Pinho, 2017), em Portugal; ou Cinco metros cuadrados (Max Lemcke, 2011), Casas para todos (Gereon Wetzeld, 2013), Os fenómenos (Alfonso Zarauza, 2014) e Bricks (Quentin Ravelli, 2017), em Espanha. Estes motivos visuais introduzem uma nova temporalidade na paisagem: o tempo da incerteza, da desorientação e da nostalgia por um futuro que já não vai acontecer. Existe, no entanto, uma diferença substancial na abordagem desta iconografia em cada lado da fronteira ibérica: as fábricas sem atividade têm sido filmadas pelos cineastas portugueses com um olhar saudosista, enquanto as obras abandonadas foram retratadas pelos realizadores espanhóis com um olhar catastrofista. A análise comparativa da omnipresença destes dois motivos visuais no cinema ibérico da austeridade pode ajudar-nos agora a perceber a origem e o sentido de alguns discursos recentes sobre o espaço urbano que têm sido desenvolvidos nestes países durante os anos da Grande Recessão.

Palavras-Chave: Cinemas Ibéricos, Cinema da Austeridade, Periferia Urbana, Iconografia da Paisagem.

\section{Abstract}

This paper aims to discuss the recurring presence of two iconographic elements related to the Great Recession (2008-2014) in the cinematic representations of Iberian urban peripheries. These two elements are closed factories and abandoned construction sites, two signs of the recent crisis in the industrial and construction sectors that have appeared in many films of Iberian Austerity Cinema, such as Horse Money (Cavalo Dinheiro, Pedro Costa, 2014), Arabian Nights (As mil e uma noites, Miguel Gomes, 2015), Saint George (São Jorge, Marco Martins, 2016) and The Nothing Factory (A fábrica de nada, Pedro Pinho, 2017), in Portugal; or Five Square Meters (Cinco metros cuadrados, Max Lemcke, 2011), Casas para todos (Gereon Wetzeld, 2013), Os fenómenos (Alfonso Zarauza, 2014) and Bricks (Quentin Ravelli, 2017), in Spain. These visual motifs introduce a new temporality into the landscape: the time of uncertainty, disorientation and nostalgia for a future that will no longer happen. There is, however, a substantial difference in the way this iconography has been addressed on each side of the lberian border: closed factories have been filmed by Portuguese filmmakers with a nostalgic gaze, while abandoned construction sites have been depicted by Spanish filmmakers with a catastrophist gaze. A comparative analysis of the omnipresence of these two visual motifs in Iberian Austerity Cinema can now help us to understand the origin and meaning of some of the recent discourses on urban space that have been developed in these countries during the years of the Great Recession.

Keywords: Iberian Cinemas, Cinema of Austerity, Urban Periphery, Landscape Iconography. 
A nossa experiência direta do espaço está ancorada no nosso cotidiano, nos lugares que melhor conhecemos: a nossa casa, o nosso quintal, o itinerário para o trabalho, eis os nossos pontos de referência. Qualquer alteração destes lugares sempre produz um ligeiro desconforto, uma desorientação passageira, mais emocional do que espacial, mesmo quando estas transformações são percebidas como algo normal e previsível: o resultado natural da passagem do tempo. A desaparição destes lugares é uma experiência mais traumática pelo seu caráter definitivo e irreversível, já que envolve também a perda do seu significado social, cultural e afetivo, embora esta perda possa ser assumida e interiorizada, mais uma vez, como o destino habitual da maioria de coisas produzidas pelo ser humano: desaparecer no final da sua vida útil. Há uma situação, no entanto, que pode afigurar-se ainda mais desestabilizadora: a ausência destes lugares, a sua supressão ontológica, a sua não-existência para o sujeito perceptivo.

Pensemos numa pessoa que, a cada dia, vai da sua casa para o trabalho. A sua experiência direta do espaço está restringida a esse itinerário: um mundo pequeno, mesmo muito limitado, mas cheio de certezas, de lugares conhecidos. Esses lugares podem ser alterados, podem desaparecer, mesmo a sua própria casa ou o seu local de trabalho podem ser demolidos, mas esses lugares permanecerão depois na sua memória como referenciais para guiar a sua capacidade perceptiva. O que acontece quando esses lugares nunca existiram - no caso daquelas pessoas que nunca tiveram lar nem emprego - ou deixam de existir - no caso, mais provável, daquelas pessoas que são expulsas das suas casas ou despedidas dos seus trabalhos? Neste segundo caso, a antiga casa e $o$ anterior local de trabalho não desaparecem, mas a pessoa perde 0 direito a entrar neles, deixa de ter uma ligação direta com estes lugares, que seguem a existir para outras pessoas. Como desenvolver, nestas circunstâncias, o trabalho de luto por um lugar que deixou de existir sem desaparecer? Onde encontrar novos espaços em que seja possível estabelecer novas relações de pertença? Quais são agora, enfim, os pontos de referência destas pessoas, no espaço e na vida?

A falta de lar e de emprego pode levar uma pessoa a uma situação de pobreza e exclusão social da qual não é fácil sair: é um problema que gera outros problemas. Este processo pode acontecer em qualquer território, mesmo naquelas sociedades em que a maioria da população, aparentemente, já resolveu tais questões: a persistência de uma crise econômica além da capacidade de resistência de uma percentagem significativa da população pode pôr em causa qualquer organização social. A Grande Recessão, neste sentido, tem sido um processo histórico muito marcante nos países periféricos da União Europeia, como Irlanda, Portugal, Espanha ou Grécia, onde a decisão dos respectivos governos de manter uma política de austeridade fiscal no início 
da década de 2010 alongou por vários anos os efeitos negativos da crise financeira global iniciada em 2008. A taxa de desemprego, por exemplo, atingiu o seu valor mais elevado no primeiro trimestre de 2013 na Península Ibérica: 17,5\% em Portugal e 26,94\% na Espanha, isto é, quase um milhão de pessoas em Portugal - 926.800 pessoas, segundo os dados do Instituto Nacional de Estatística português - e mais de seis milhões de pessoas na Espanha -6.278 .200 pessoas, desta vez segundo os dados do Instituto Nacional de Estatística espanhol. Nessa altura, os despejos chegaram a ser infelizmente habituais na Espanha, onde foram iniciados até 523.740 processos de execuções imobiliárias entre os anos 2006 e 2013, segundo as cifras do Conselho Geral do Poder Judicial deste país (MÉNDEZ, ABAD \& ECHAVES, 2015: 85). A combinação destas duas estatísticas evidencia a existência de um coletivo de pessoas sem casa nem trabalho, sem lugar onde estar nem lugar para onde ir. Tentar saber agora como era a experiência direta do espaço destas pessoas nos anos da recessão pode parecer uma frivolidade, mas essa experiência é significativa para compreender a sua percepção do mundo e, mais importante, o seu contributo para a criação de uma imagem coletiva do meio ambiente (LYNCH, 1982: 16). ${ }^{3}$ Quais são, portanto, as principais imagens ambientais da Grande Recessão na Península lbérica? Quais são as paisagens sociais e culturais que deixou a austeridade no imaginário coletivo das sociedades ibéricas?

Qualquer paisagem é um construto (MADERUELO, 2007: 12), uma elaboração mental que surge do encontro dessa experiência direta e cotidiana do espaço com uma experiência estética e histórica construída socialmente: vemos aquela imagem ambiental que antes alguém nos mostrou, que aprendemos a perceber ao longo da nossa vida e que interiorizamos através das artes visuais. Essas artes, como a pintura, a fotografia ou o cinema, funcionam como dispositivos de mediação entre o olhar e 0 espaço: o olhar dos artistas estabelece uma visão do espaço que dá lugar a imagens ambientais que, às vezes, podem passar a fazer parte do imaginário coletivo. Esta visão, aliás, é um registro dum espaço onde convivem várias temporalidades: o tempo longo do substrato geológico e o tempo curto das contingências históricas, como a Grande Recessão, que são as que provocam a maior parte das alterações perceptíveis pelas pessoas no espaço e na paisagem.

${ }^{3} \mathrm{O}$ geógrafo Kevin Lynch explica o processo de formação de uma imagem do meio ambiente - an environmental image - desta forma: "As imagens do meio ambiente são o resultado de um processo bilateral entre o observador e o meio. $O$ meio ambiente sugere distinções e relações, e o observador com grande adaptação à luz dos seus objetivos próprios - seleciona, organiza e dota de sentido aquilo que vê" (LYNCH, 1982:16). 
O cinema é, talvez, a arte que melhor tem representado estas alterações no último século. A sua capacidade para construir uma percepção do mundo vai além do papel clássico da arte - que seria, segundo os sociólogos Gilles Lipovetsky e Jean Serroy, fazer ver, através da obra, o que inicialmente não se vê na realidade - porque o cinema conseguiu intervir diretamente sobre o real através da produção de realidades extracinematográficas formatadas a partir de referentes cinematográficos (LIPOVETSKY \& SERROY, 2009: 320). Neste feedback contínuo entre a vida e a arte, entre o real e a sua representação, algumas imagens ambientais podem tornar-se em motivos visuais recorrentes e mesmo em ícones que identificam um tempo determinado: a repetição destas imagens dá lugar aos motivos, enquanto a utilização sistemática destes motivos está na origem dos ícones. Estas transformações podem responder às lógicas de consumo - lugares e paisagens que estão na moda - ou resultar da utilização destas imagens como alegorias visuais para sugerir ou sintetizar uma ideia, isto é, para fazer um comentário sobre o presente e sobre o real. A causa da persistência de algumas imagens ambientais no imaginário coletivo seria, portanto, o seu poder de significação, a sua capacidade para simbolizar e transmitir ideias, já que as alegorias visuais são percepções que funcionam como interpretações; imagens polissêmicas que convidam a aprofundar nos seus possíveis sentidos para além da narração.

Dito isto, chegou a altura de anunciar o propósito específico deste artigo: identificar e interpretar alguns destes ícones no cinema ibérico da austeridade, um ciclo de filmes realizados na Península Ibérica entre os anos 2006 e 2018, que retratam ou refletem os efeitos e consequências da Grande Recessão no nível temático, formal ou alegórico (cf. VILLARMEA ÁLVAREZ, 2018: 17). A maioria destes filmes decorre em ambientes urbanos, por serem os espaços onde mora a maior parte da população, pelo que não é estranho que os dois principais ícones da austeridade sejam justamente espaços urbanos falhados que já não conseguem cumprir a função para a qual foram concebidos: são, como veremos, as fábricas sem atividade e as obras abandonadas, dois signos da paralisia no setor industrial e na construção civil durante os anos da recessão. Estes motivos visuais funcionam como alegorias deste período, isto é, como um âncora temporal que introduz uma nova temporalidade na paisagem: o tempo da incerteza, da desorientação e da nostalgia por um futuro que já não vai acontecer.

\section{A cidade da austeridade}

Um homem de trinta ou quarenta anos passeia pelos jardins da zona turística de Madrid, entre a Praça de Espanha e o Palácio Real. Observa o lugar e faz fotografias com o intuito de iniciar conversas - sempre em inglês - com outras pessoas, normalmente turistas jovens que viajam sozinhas. Por três vezes conseguirá tornar-se 
íntimo destas mulheres e acabará fazendo amor com elas. Porém, a terceira mulher perceberá que este homem não é quem diz ser - um artista com projeção internacional -, mas alguém que simula ser quem não é para encher o seu vazio vital, provocado, entre outras causas, pela recessão: o homem perdeu o seu trabalho, a sua casa e a sua namorada - por esta ordem - e está agora a passar o verão na casa de um amigo à espera de um milagre que mude a sua situação. Esta é a história de Madrid above the moon (Miguel Santesmases, 2015), um filme espanhol sobre o desejo de recomeçar, de ser outro; mas também sobre o autoengano, sobre as mentiras que nos ajudam a paliar as nossas desgraças: este homem, em lugar de enfrentar os seus problemas, prefere criar um simulacro de vida no centro da cidade, onde sabe que não vai encontrar nenhuma pessoa conhecida porque há tempo, depois de décadas de gentrificação e turistização, que quase ninguém consegue morar lá.

Os centros das cidades estão a virar decorados em muitos lugares do mundo, quando menos, desde o final dos anos noventa, como argumentam Gilles Lipovetsky \& Jean Serroy (2009: 323). Nos últimos dez anos, no ciclo do cinema da austeridade, poucos títulos têm representado os principais centros urbanos da Península Ibérica: apenas alguns feel-good movies portugueses, como Os gatos não têm vertigens (António-Pedro Vasconcelos, 2014) ou Tristeza e alegria na vida das girafas (Tiago Guedes, 2019), e alguns filmes independentes espanhóis marcados por um tom voluntariamente ingênuo, como Ilusión (David Castro, 2013), Los ilusos (Jonás Trueba, 2013), Selfie (Víctor García León, 2017) ou o próprio Madrid above the moon. O centro urbano é, nesta altura, um espaço onde fantasiar, onde situar ficções edulcoradas que mostram a vida melhor do que é. Talvez por este motivo a praça, o grande ícone dos protestos anti-austeridade, está quase ausente no cinema de ficção desta década: as grandes manifestações e assembleias do Movimento 15-M ou do protesto da "Geração à Rasca" quase não aparecem nas ficções ibéricas da austeridade, ${ }^{4}$ já que a esperança que despertou o convívio cidadão nas praças - a esperança e o desejo de uma mudança radical na gestão política e econômica do estado - não pôde ser ainda ficcionalizada por falta de distância temporal e emocional que evite a sua banalização, isto é, que evite que essa esperança seja deturpada ou esvaziada de significado numa reconstrução cinematográfica prematura.

A vida cotidiana, infelizmente, há décadas que já não está nos centros urbanos: Pierre Sorlin tem mesmo escrito sobre a destruição cinematográfica das cidades

\footnotetext{
${ }^{4}$ Algumas exceções a esta tendência seriam a ficção documental portuguesa As Mil e Uma Noites (Miguel Gomes, 2015) ou o falso documentário espanhol Selfie. O Movimento 15-M, no entanto, tem sido retratado em muitos títulos de não-ficção realizados por cineastas espanhóis e estrangeiros (cf. SÁNCHEZ-RODRÍGUEZ, 2018: 63-79).
} 
europeias a partir da segunda metade dos anos sessenta, quando os cineastas, seguindo aos moradores, deslocaram-se para as novas periferias dispersas à procura de novas histórias (1996: 127-133). A cidade da austeridade nos cinemas ibéricos é assim uma cidade sem centro, um conjunto de bairros periféricos cujos moradores fazem tudo o que podem para resistir à tempestade econômica. As imagens ambientais mais frequentes nesta periferia cinematográfica são trechos de paisagens residenciais, pósindustriais e liminares onde sempre há algum prédio desabitado, algum solar vazio, alguma fábrica sem atividade ou alguma obra sem concluir.

As paisagens residenciais, em particular, expressam uma desconfortante sensação de isolamento: os prédios e apartamentos são habitualmente representados como espaços opressivos, mesmo patibulares, como acontece em Hermosa juventud (Jaime Rosales, 2014), Magical girl (Carlos Vermut, 2014), Techo y comida (Juan Miguel del Castillo, 2015), São Jorge (Marco Martins, 2016), Colo (Teresa Villaverde, 2017) ou no episódio 'Os donos de Dixie', incluído no segundo volume da trilogia As mil e uma noites (Miguel Gomes, 2015). As paisagens pós-industriais, pelo seu lado, são mais comuns no cinema português, em títulos como Ruínas (Manuel Mozos, 2009), Cavalo Dinheiro (Pedro Costa, 2014), São Jorge ou A fábrica de nada (Pedro Pinho, 2017), que chamam a atenção para o lento declínio, por vezes irreversível, dos antigos bairros operários e espaços industriais que ficaram obsoletos. As paisagens liminares, por último, mostram a fronteira porosa que separa o espaço urbano do espaço rural, onde há uma mistura instável de elementos pertencentes a diferentes universos conceituais: vestígios do mundo urbano, rural, natural, industrial ou comercial sem uma hierarquia clara entre eles. Estas paisagens intermédias (LERUP, 2000: 157-158) ou transgênicas (DOMINGUES, 2009: 246-249) aparecem nos filmes que tratam sobre o processo de construção de novos prédios fora de portas, como Cinco metros cuadrados (Max Lemcke, 2011), Os fenómenos (Alfonso Zarauza, 2014), Berserker (Pablo Hernando, 2015) ou As cidades e as trocas (Luísa Homem \& Pedro Pinho, 2014), mas também nalguns trabalhos portugueses que retratam estes espaços rururbanos como lugares de resistência e mesmo de libertação, como Colo, $A$ fábrica de nada ou o episódio 'O Inebriante Canto dos Tentilhões' de As mil e uma noites .

O grande ícone das paisagens residenciais é, obviamente, o esqueleto de concreto armado dos prédios inacabados, isto é, uma construção abandonada antes mesmo de ser acabada. Estes prédios são lares truncados, casas onde já não vai morar ninguém: cadáveres imobiliários que podem dar origem, segundo Joan Miquel Gual, a discursos críticos e militantes (2019: 60,168). O ícone equivalente das paisagens pósindustriais é, entretanto, a fábrica parada ou fechada, à espera de retomar a atividade ou ser demolida definitivamente. Estes dois ícones podem aparecer em qualquer lugar 
da periferia urbana, mas costumam estar no limite mesmo da área urbana, fazendo parte, portanto, de alguma paisagem liminar. A ubiquidade deste tipo de estruturas na cidade e no cinema durante os longos anos da recessão fez destes motivos visuais um ominoso lembrete da volatilidade da riqueza e da fragilidade do presente.

\section{Fábricas sem atividade}

O filme português Ruínas - que teve a sua estreia em maio de 2009, durante o Festival IndieLisboa, onde ganhou o prêmio de melhor longa-metragem da competição nacional - retrata um país assombrado pelo seu passado. O título já anuncia o seu conteúdo: um conjunto de sequências não narrativas que mostram a presença de ruínas por toda a geografia portuguesa. Estas ruínas, no entanto, não são sítios arqueológicos nem monumentos históricos que atraiam turistas, mas sim espaços residenciais, produtivos e de lazer que foram abandonados depois de ficar obsoletos; como o Bairro Operário da CUF, no Barreiro, na margem sul da foz do Tejo, ou as minas a céu aberto de São Domingos, no Alentejo, perto da fronteira meridional entre Portugal e Espanha. Nenhum dos vinte e três locais que aparecem no filme é, na verdade, muito antigo: a maioria data dos anos do Estado Novo, o regime fascista que vigorou em Portugal entre os anos 1933 e 1974, pelo que estes lugares podem ser considerados ruínas da modernidade (cf. HELL \& SCHÖNLE, 2010): não a modernidade heroica e triunfante dos países centrais do capitalismo, mas uma versão local e incompleta, própria dos países semiperiféricos do sistema-mundo, que tem ficado associada ao salazarismo.

A sucessão de lugares na metragem de Ruínas não responde a uma lógica cronológica nem geográfica, mas sim emocional, como se o realizador deste filme, Manuel Mozos, quisesse dar a impressão de que todo o país estava há décadas negligenciado, uma ideia que já aparecera uns anos antes no travelogue Um pouco mais pequeno que o Indiana (Daniel Blaufuks, 2006). Estes dois filmes podem ser interpretados como advertências à sociedade portuguesa do que estava por vir, isto é, como premonições da Grande Recessão e do Cinema da Austeridade. Neste sentido, o estado de abandono que apresentam os antigos espaços produtivos mostrados em Ruínas reflete a diminuição gradual de atividade nas fábricas e áreas industriais portuguesas no início do século XXI, um processo que resulta do esgotamento do modelo produtivo luso: algumas grandes fábricas começaram a encerrar na primeira década deste século, antes mesmo da recessão, devido à falta da competitividade internacional da economia portuguesa por causa da especialização dos seus setores de exportação em produtos que se encontravam em processo de desvalorização internacional - como seria, por exemplo, o caso do setor têxtil (cf. SANTOS, 2012: 21). Nestas circunstâncias, a recessão simplesmente acelerou este processo, impedindo a 
transformação e recuperação da indústria portuguesa no curto prazo: o número de trabalhadores empregados no setor secundário atingiu a sua cota mais alta no ano 2000 , com 1.741.700 pessoas; mas esta cifra desceria depois até as 1.049 .700 pessoas no pior momento da recessão, o ano 2013, embora depois experimentasse uma ligeira recuperação até chegar às 1.209.200 pessoas em 2018. Este decréscimo supõe, em qualquer caso, uma importante redução da força de trabalho industrial portuguesa, que passou do 34,55\% da população ativa em 2000 para o 23,60\% em 2013 e o 24,85\% em 2018 (PORDATA, 2019).

O ícone das fábricas sem atividade aparece, para além de Ruínas, em meia dúzia de filmes portugueses desta última década: são as antigas fábricas têxteis do Vale do Rio Ave, protagonistas de títulos de não-ficção como Vidros partidos (Víctor Erice, 2012) ${ }^{5}$ ou Revolução Industrial (Tiago Hespanha \& Frederico Lobo, 2014); são também os Estaleiros Navais de Viana do Castelo, filmados por Miguel Gomes na altura da sua extinção como empresa pública no prólogo de As mil e uma noites ; são as ruínas do escritório e da oficina da Sociedade Construções Amadeu Gaudêncio que Ventura visita em Cavalo Dinheiro; e são, por último, as fábricas da periferia lisboeta onde trabalham os personagens de São Jorge e A fábrica de nada, dois filmes que começam justamente quando estas fábricas suspendem suas atividades. Todos estes lugares eram os polos que organizavam a estrutura socioeconômica das suas áreas geográficas, pelo que a sua representação no cinema da austeridade costuma salientar a sua posição central, hierárquica e mesmo panóptica dentro da paisagem. Vários cineastas, aliás, chegaram a filmar a visão destas fábricas desde o interior dos prédios onde moram os seus antigos trabalhadores, como é o caso de Marco Martins em São Jorge ou de Pedro Pinho em $A$ fábrica de nada, lembrando, desta forma, a antiga interdependência, hoje obsoleta, entre a força e o local de trabalho (cf. BAUMAN 2000: 58).

A desindustrialização supôs um corte na longa e rica história antropológica destas áreas, que começam agora a ser retratadas como paisagens truncadas, isto é, como paisagens vividas e trabalhadas com grande intensidade pelos seus moradores que nesta altura, infelizmente, devem enfrentar um presente exausto e um futuro incerto. Muitos cineastas filmam estas áreas com um tom melancólico que revela uma posição ambivalente a respeito destes espaços produtivos: por uma parte, os realizadores são conscientes da sua obsolescência; mas, por outra parte, expressam também um sentimento de nostalgia pelos desejos de progresso social e material que representavam

\footnotetext{
${ }^{5}$ Este curta-metragem sobre a Antiga Fábrica de Fiação e Tecidos do Rio Vizela faz parte do filme coletivo Centro Histórico, realizado dentro do programa de produção cinematográfica do evento Guimarães 2012 Capital Europeia da Cultura. Os outros realizadores que participaram neste filme foram Aki Kaurismäki, Pedro Costa e Manoel de Oliveira.
} 
estas fábricas na sua origem. Esta volta para um imaginário industrial, que nunca chegou a atingir completamente as suas expectativas, supõe uma reação ante a involução social provocada pela recessão, e pode ser interpretada como uma tentativa de importar desde o passado a confiança do presente no seu poder de transformação; uma confiança que, segundo Zygmunt Bauman, está na base do conceito de progresso histórico (2000: 132).

Algumas destas representações nostálgicas e melancólicas dos ambientes pósindustriais lembram a forma com que os cineastas modernos portugueses retratavam as comunidades rurais e marinheiras nos anos sessenta e setenta: Paulo Rocha, por exemplo, filmou o esgotamento do modo de vida associado à pesca artesanal em Mudar de vida (1966), título em que há uma sequência na qual o seu protagonista procura trabalho numa fábrica. Essa cena reflete a passagem de camponeses, pescadores e marinheiros do setor primário para o secundário, mas Rocha apenas mostra o interior dos escritórios da fábrica, prescindindo das imagens do seu exterior. A metragem de Mudar de vida não inclui, na verdade, nenhuma paisagem industrial, porque o foco deste filme está naquilo que desaparece, na comunidade piscatória do Furadouro, e não naquilo que o substitui, nas novas áreas industriais que naquela altura estavam a aparecer em muitas cidades portuguesas. O olhar de Paulo Rocha para esta comunidade não é assim tão diferente do olhar de Pedro Costa para os imigrantes caboverdianos em Cavalo Dinheiro ou do olhar de Pedro Pinho para os operários industriais em $A$ fábrica de nada. Estas similitudes sugerem certa continuidade no olhar dos cineastas portugueses para as alterações na paisagem dentro do tempo curto das contingências históricas: uma continuidade saudosista no olhar, no tom e no discurso como reação e resposta às rupturas sociais provocadas pelo esgotamento dos ciclos econômicos.

O saudosismo, no entanto, tem um risco evidente: pode dar lugar a discursos reacionários que idealizam o passado e branqueiam as suas disfunções. $O$ ícone das fábricas sem atividade está exposto a este risco: tem a capacidade de expressar uma forte nostalgia pelos "futuros-presentes" do Século XX - os futuros imaginados na modernidade, no presente dos anos cinquenta, sessenta e setenta do século passado, segundo a terminologia de Andreas Huyssen - enquanto simboliza a transformação destas fábricas em lugares varados no "passado-presente" - o passado comemorado e venerado na pós-modernidade, no presente das duas últimas décadas do Século XX e as duas primeiras do século XXI (HUYSSEN, 2014; a tradução é minha). Como evitar, então, que o passado, como parece sugerir Manuel Mozos em Ruínas, acabe vampirizando o presente?

Costa e Pinho utilizam diferentes estratégias nos seus respectivos filmes para resolver esta questão. A sede abandonada da Sociedade Construções Amadeu 
Gaudêncio funciona, em Cavalo Dinheiro, como um blinking space, um espaço intermitente que representa simultaneamente o passado e o presente de um lugar, permitindo, portanto, que os personagens e os espectadores possam voltar para 0 passado, para as experiências vividas nesse lugar, sem abandonar o presente da filmagem ou da projeção (cf. VILLARMEA ÁLVAREZ, 2016: 33-34; 2019: 111-112). Ventura, o personagem principal deste filme, comporta-se nesse lugar como se fosse mais um dia de trabalho da sua juventude: o seu corpo reproduz a sua rotina quotidiana; vai à casa de banho, vai ao vestiário, vai à oficina e, por último, vai ao escritório. A forma com que Pedro Costa encena esta sequência permite a passagem das ruínas do presente para a memória do passado: por uma parte, durante a rodagem, o realizador filma o tempo necessário para que Ventura, como intérprete, possa entrar em transe e reviver o passado; e depois, durante a pós-produção, utiliza a tecnologia digital para apagar fragmentos do quadro - que ficam negros, como no cinema expressionista - e salientar, assim, aqueles elementos que ajudam a fazer a ligação entre o passado e 0 presente, como o telefone.

A Sociedade Construções Amadeu Gaudêncio é um lugar, como acontece com quase todos os espaços retratados em Cavalo Dinheiro, onde há uma extraordinária acumulação de tempo, de experiências e de lembranças - boas e más - que ligam as tarefas desenvolvidas neste local com a exploração sofrida pelos trabalhadores emigrantes em qualquer latitude e circunstância. A voz e a figura de Ventura é o veículo através do qual Costa reconstrói as relações laborais entre estes trabalhadores e os empresários que os exploravam, sintetizadas em vários monólogos que reproduzem trechos de conversas entre o personagem e o patrão desta sociedade: primeiro, Ventura queixa-se da diminuição do seu salário, depois negoceia a compra de tijolos e sacos de cimento para construir a sua casa - passando, assim, de funcionário a cliente da própria empresa para a qual trabalha- e finalmente despede-se do patrão enquanto sai do escritório com a cabeça baixa, o gesto submisso e um envelope com o seu escasso salário - apenas uma velha nota de mil escudos. Estes monólogos trazem à tona uma memória da exploração que Costa abstrai e descontextualiza através do distanciamento temporal - esses quarenta anos que já passaram entre a juventude e a velhice do personagem - e através, sobretudo, do estranhamento causado pelas formas utilizadas - a diç̧ão sincopada de Ventura, sempre rígido, sempre lento e sempre a tremer, no escuro - com o intuito de representar o caráter atemporal e sistêmico dessa exploração antes e agora, no tempo da revolução e também no tempo da recessão.

Pedro Pinho, entretanto, concebe a fábrica paralisada que protagoniza o seu filme como um espaço de luta e de aprendizagem, como um campo de provas onde os operários devem tomar a iniciativa para testar outro tipo de relações de produção. A 
primeira metade da metragem, filmada com um estilo neorrealista a meio caminho entre o drama social e a ficção documental, mostra a perda de atividade na fábrica desde o momento em que os operários frustram uma tentativa de deslocar as máquinas até a sequência na qual percebem, com grande surpresa, que a administração da sua empresa desapareceu, deixando todo o seu escritório vazio. Nessa altura, quando os personagens já têm discutido os prós e os contras de ocupar a fábrica, o estilo do filme começa a mudar: o relato fica então congelado durante um longo excurso reflexivo do que não sairá até a chegada de uma insólita sequência musical, profundamente autoparódica, que abre a porta à possibilidade de desenvolver uma autocrítica explícita, dentro do próprio filme, dos seus diferentes dispositivos de representação.

Quando deixa de produzir elevadores e passa a produzir esse "nada" a que se refere o título, a fábrica converte-se num agente que possibilita a mobilização coletiva, porque força os operários a decidirem entre aceitar as propostas da empresa - neste caso, a rescisão dos seus contratos em troca de uma indenização econômica - ou defender os seus empregos através de distintas estratégias de luta - a greve, a ocupação, a autogestão etc. Pinho entende esse nada, o vazio que resulta da falta de atividade, como um ponto de partida para a criação de "mundos possíveis" (cf. NOLAN, 2002; a tradução é minha) - isto é, para desenvolver qualquer nova concepção mental ou formulação linguística que permita pensar na existência hipotética de uma outra forma de fazer as coisas ou de experimentar uma situação. A fábrica de nada produz, portanto, um espaço para a discussão e para a ação coletiva dos operários e do cineasta, já que estabelece um paralelismo explícito entre as dúvidas dos operários como autogerir uma fábrica? - e as dúvidas do cineasta - como representar este conflito sem cair nos clichês do cinema social? -, sem oferecer mais soluções que o próprio esforço de procurar e testar diferentes soluções. Assim, longe da nostalgia passiva pelos futuros radiosos imaginados no passado, o ícone da fábrica sem atividade reivindica aqui a esperança ativa da incerteza: o desejo do presente de criar um futuro que esteja livre das limitações impostas no passado.

\section{Obras abandonadas}

A presença de prédios em construção, inacabados ou abandonados, é mais frequente no cinema espanhol do que no cinema português pelo maior peso da construção civil na economia desse país, que gerou um excedente desproporcionado de casas vazias durante os anos da recessão nos chamados "territórios do tijolo" nomeadamente, a costa mediterrânea, a área metropolitana de Madrid e as llhas Baleares e Canárias (MÉNDEZ, ABAD \& ECHAVES, 2015: 124, a tradução é minha). Este ícone, no entanto, também está associado ao simbolismo que ganhou a vivenda 
urbana na sociedade e no cinema espanhol a partir do terceiro quarto do século XX, quando o mercado imobiliário não conseguia satisfazer a demanda de habitação criada pela chegada massiva de camponeses às cidades: assim, títulos que combinam o humor ácido com a crítica social, como El inquilino (José Antonio Nieves Conde, 1957), El pisito (Marco Ferreri, 1958) ou El verdugo (Luis García Berlanga, 1963), desenvolvem argumentos bizarros relativamente a como seus personagens devem fazer coisas extremas para poder arranjar uma vivenda em Madrid. ${ }^{6}$ Os prédios em construção representam, nesta altura, uma projeção futura do desejo de bem-estar e ascensão social da população; mas este otimismo será substituído, no cinema da austeridade, pela ideia de excesso e de estancamento durante a recessão.

O motivo visual das obras abandonadas, transformadas agora em ruínas imobiliárias com maior valor de troca que valor de uso, tem sido interpretado por Joan Miquel Gual como um lembrete da desigualdade social e do abuso do meio ambiente produzidos pelo modelo econômico neoliberal (2019: 65,172). Este ícone, presente em romances como En la orilla (CHIRBES, 2013) ou projetos fotográficos como Ruinas Modernas. Una Topografia del lucro (SCHULZ-DORNBURG, 2012), aparece fugazmente em filmes como Vidas pequeñas (Enrique Gabriel, 2010), Mapa (Elías León Siminiani, 2012), Los chicos del puerto (Alberto Morais, 2013), Somos gente honrada (Alejandro Marzoa, 2013), Madrid above the moon ou El olivo (Icíar Bollaín, 2016), mas será nas ficções Cinco metros cuadrados e Os fenómenos que funcionará como uma peça central do seu discurso. O primeiro destes títulos - filmado na costa valenciana, no epicentro mesmo dos territórios do tijolo - conta uma história de proprietários frustrados e propriedades truncadas: o casal protagonista de Cinco metros cuadrados investe - e perde - toda a sua poupança na compra de um apartamento dentro de um prédio que nunca se chegará a terminar por ter sido construído no interior de uma área protegida, de forma que o seu esqueleto de concreto simbolizará simultaneamente a paralisação do seu projeto de vida e a destruição da paisagem. Os fenómenos, pelo contrário, foi filmado na costa galega, longe dos territórios do tijolo, e interessa-se por outro relato: a ascensão e queda dos operários da construção civil, que antes da recessão experimentaram o efeito riqueza da bolha imobiliária, quando podiam chegar a ganhar mais do triplo do seu salário habitual; mas depois, com a chegada da crise, ficaram de súbito sem trabalho e sem dinheiro, varados em cadáveres imobiliários que ninguém

\footnotetext{
${ }^{6} \mathrm{Em}$ El inquilino, o protagonista procura desesperadamente uma nova casa enquanto estão a demolir o prédio no qual mora com a sua família; em El pisito, um jovem decide casar com uma idosa, proprietária de um residencial num apartamento situado no centro da cidade, para poder herdar essa vivenda depois da sua morte e evitar que todos os seus hóspedes fiquem sem morada; e por último, em El verdugo, um jovem coveiro casa com a filha de um velho carrasco e aceita exercer o emprego do seu sogro para ter direito a um apartamento num prédio de habitação social.
} 
quer terminar nem comprar enquanto tentam malbaratar carros e vivendas que adquiriram a crédito como signos de um status social que nunca chegaram a atingir.

Uma variação iconográfica dos prédios em construção são as paisagens suburbanas quase desabitadas, como as que aparecem em Berserker. um dos personagens secundários deste filme, por exemplo, mora mesmo na fronteira da urbanização, num prédio que está em frente a uma grande área vazia sem utilidade agrícola que serve como reserva de território para várias cidades da periferia sul de Madrid. ${ }^{7}$ Estas paisagens suburbanas são os espaços para os quais toda uma geração de jovens precários está a ser expulsa - espaços liminares entre o médio natural e o médio construído que ainda não foram completamente ocupados pelos seus novos moradores e que, portanto, são o contrário de uma paisagem vivida, isto é, são nãolugares, espaços que ainda não têm uma tradição antropológica consolidada (cf. AUGE, 1994).

Algumas destas localizações podem mesmo aparecer repetidas em vários filmes, como acontece com o pátio interior de um bloco de prédios inacabados que tem um grande grafite numa parede onde se pode ler a seguinte frase: "cada dia as tuas ilusões cruzam-se com as nossas". Este lugar, que foi filmado quase desde a mesma posição em Indignados (Tony Gatlif, 2012) e Bricks (Quentin Ravelli, 2017), está em Ciudad Valdeluz, uma cidade dormitório da periferia leste de Madrid - retratada também nos documentários Casas para todos (Gereon Wetzel, 2013) e País de todo a 100 (Pablo Llorca, 2014) - que nunca chegou a atingir o número de moradores para que foi planificada: a ideia original era que morassem lá umas 30.000 pessoas de classe média alta - nomeadamente, profissionais que fossem todos os dias a Madrid no trem de alta velocidade - mas apenas tinha 2.874 vizinhos em 2015 com um perfil socioeconômico bem diferente - mileuristas, pessoas divorciadas e casais jovens com filhos pequenos (cf. VILLARINO, 2015). O desajuste na escala desta cidade dormitório representa fisicamente o fracasso dos projetos megalômanos anteriores à recessão, pelo que Ciudad Valdeluz tem atraído o olhar de vários cineastas estrangeiros interessados especificamente na representação da crise imobiliária espanhola através do ícone das obras abandonadas, como o alemão Gereon Wetzel ou o francês Quentin Ravelli.

Bricks, o filme deste último realizador, acompanha o processo de fabricação do tijolo, um material que já tivera grande importância no discurso visual de um título português anterior: As cidades e as trocas, outro trabalho de não-ficção realizado nas ilhas de Cabo Verde pela dupla formada por Luísa Homem e Pedro Pinho. Estes três

${ }^{7}$ Esse prédio, como se pode ver no plano no qual o protagonista do filme sai dele, está na Rua Arquimedes de Leganés, uma via sem saída encerrada entre autoestradas e terrenos vagos que separam as cidades de Leganés, Fuenlabrada, Móstoles e Alcorcón. 
cineastas - Ravelli, Homem e Pinho - deslocam-se para outros países com o intuito de filmar literalmente a transformação da terra - a matéria que conforma a paisagem - em tijolo - o elemento básico da indústria da construção civil. As cidades e as trocas e Bricks são, assim, filmes que utilizam a materialidade do tijolo para abordar as lógicas abstratas, imateriais, globais e pós-coloniais do capital transnacional, que está a incentivar há décadas a especialização setorial das economias ibéricas - e agora, também, da cabo-verdiana - na construção civil e no turismo internacional.

A questão que colocam estes documentários é a influência que o perfil socioeconômico dos futuros moradores dessas novas construções pode ter na experiência da paisagem. Quem vai morar nessas casas? Os prédios de Ciudad Valdeluz seguem ainda quase vazios, enquanto os apartamentos e resorts turísticos cabo-verdianos não são para os cidadãos deste país (que seguem a morar em casas bem mais humildes), mas para cidadãos estrangeiros - como os cineastas - que nem sempre vão se integrar à sociedade local. O problema, portanto, é que estas tipologias residenciais introduzem uma projeção de futuro sobre a paisagem diferente daquela que existia antes da recessão.

A transformação da paisagem para uso turístico é um processo que começou há mais de meio século na Península lbérica e tem já afetado a boa parte do seu litoral, sobretudo na costa mediterrânea. Nesta altura, os grandes resorts à beira-mar são as fábricas do presente, cujos trabalhadores já não produzem objetos materiais, mas experiências imateriais. Porém, da mesma forma que há fábricas paradas ou fechadas, também há resorts inacabados e falhados, como Marina d'Or Golf, na costa norte do País Valenciano, ou Fortuna Hill Nature and Residential Golf Resort, no interior da região de Múrcia, mais dois cadáveres imobiliários fotografados por Julia Schulz-Dornburg no seu livro Ruínas Modernas e filmados também por Pablo Llorca no seu documentário País de Todo a 100.

Este último travelogue oferece um itinerário crítico pelos territórios do tijolo, misturando imagens observacionais com um comentário ficcional; um dispositivo cinematográfico que já fora utilizado vinte anos antes pelo realizador britânico Patrick Keiller nos seus filmes London (1994), Robinson in Space (1997) e Robinson in Ruins (2010). A história fictícia de um cidadão espanhol emigrado em Berlim, que volta de férias para o seu país com um amigo finlandês no pior momento da recessão, serve aqui para mostrar a inquietação social, representada através de várias manifestações de protesto nas ruas e praças de Madrid, e também a paisagem ferida que surge da bolha imobiliária, caracterizada pelas obras abandonadas desses resorts inacabados e pelos espaços vazios, sem vida, das novas cidades dormitório da periferia madrilena, como Seseña ou a própria Ciudad Valdeluz. 
Llorca, no entanto, também encontra algum lugar na costa mediterrânea que parece estar ainda a salvo deste processo de transformação da paisagem para uso turístico: o itinerário que supostamente seguem os personagens de País de todo a 100 chega numa sequência à aldeia de Puntas de Calnegre, na costa murciana, onde "um campo de futebol à beira-mar é", como se diz no comentário, "o signo mais preciso de que um lugar ainda não tem sido colonizado pelo turismo" (a tradução é minha). Este motivo visual - o campo de futebol à beira-mar - aparece também nos últimos minutos de As Cidades e as trocas, um filme que termina com uma sequência relativamente otimista - e, se calhar, também um bocado ingênua - que sugere que a vida popular, tradicional dos cabo-verdianos (representada aqui pelo trabalho de irrigação no quintal do Manel, um dos personagens que aparecem com mais frequência na metragem) ainda continua para além das atividades do setor turístico.

O quintal cultivado é, pela sua parte, um motivo visual que significa o contrário das obras abandonadas: simboliza a continuidade das paisagens vividas frente à ruptura das paisagens truncadas. Semelhante ao jardim, ou ao parque, o quintal é um local de encontro entre as pessoas e a natureza, mas a sua finalidade produtiva sempre introduz uma dimensão económica na paisagem, de forma que o quintal fica habitualmente associado com o mundo rural e o setor primário, embora também haja quintais urbanos. O crescimento das cidades nas últimas décadas provocou a transformação de muitos quintais em jardins, paralelamente à conversão do solo rústico em solo urbano. Mas os quintais, ou os espaços produtivos associados com o setor primário, estão a resistir e mesmo a recuperar o terreno perdido por causa da recessão: a aparição de um excedente de territórios urbanizados não habitados no perímetro exterior das cidades está a acrescentar a tensão que já existia nestas paisagens transgênicas entre as atividades agrícolas tradicionais e os novos usos residenciais, dando lugar a imagens surpreendentes que se repetem no cinema espanhol e português, como a presença de um rebanho de ovelhas junto a um conjunto de chalés inacabados - em Casas para todos - ou ao pé de um prédio de apartamentos - no episódio 'Os Donos de Dixie' de As mil e uma noites. Será que a natureza vai tomar conta agora destes espaços, como já fez com tantas outras ruínas? O ícone das obras abandonadas, por enquanto, coloca uma questão pungente: o que fazer com estes lugares antes que seja tarde demais?

\section{Conclusões: sobreviver ao futuro}

Os cinemas ibéricos reagiram à chegada da Grande Recessão com histórias e imagens que salientam a paralisia e às vezes mesmo a destruição das expectativas de vida de muitas pessoas. Este corte súbito nas projeções de futuro anteriores à crise atinge uma dimensão alegórica e coletiva nas imagens ambientais da cidade da 
austeridade. A sua implosão lenta e descontrolada é mais visível nas periferias, onde as velhas áreas industriais veem ameaçada a sua continuidade como paisagens vividas e trabalhadas, enquanto as novas áreas residenciais estão a ser abandonadas antes mesmo de poderem ser vividas ou trabalhadas. Estas paisagens truncadas, que deixaram de ser ou que já não serão, encontram a sua melhor expressão nos motivos visuais da fábrica sem atividade e das obras abandonadas, dois ícones da cidade da austeridade que têm sido filmados com um olhar ligeiramente diferente a cada lado da fronteira ibérica: um olhar saudosista no caso português, caracterizado pela contemplação insistente e obsessiva dos vestígios do passado, mesmo quando esse passado não tem sido mais feliz do que o presente; e um olhar catastrofista no caso espanhol, que mostra os resultados não desejados dos projetos megalômanos concebidos antes da crise com uma mistura de espanto, alarme e aflição, pondo o foco na desproporção da sua escala e na dificuldade para reverter os seus efeitos. Estes dois olhares retratam o presente desde a consciência do passado: uma consciência ensimesmada e esperançada, no caso português, que se torna mais crua e trágica no caso espanhol. A vida, entretanto, continua além destas fábricas e destas obras, além do futuro que já não vai acontecer, pelo que alguns cineastas, os mais afoitos, tentaram dar um significado menos passivo e mais otimista a estes ícones - as fábricas e as obras como espaços de possibilidade - num esforço, se calhar ingênuo, por vislumbrar outras formas de habitar - e, portanto, de transformar - as ruínas da recessão.

\section{Bibliografia}

AUGÉ, Marc. Não-lugares. Introdução a uma antropologia da supermodernidade. Campinas: Papirus Editora, 1994. Press, 2000.

BAUMAN, Zygmunt. Liquid Modernity. Cambridge, UK \& Malden, MA: Polity

CHIRBES, Rafael. En la orilla. Barcelona: Editorial Anagrama, 2013.

DOMINGUES, Álvaro. A Rua da Estrada. Porto: Dafne Editora, 2009.

GUAL, Joan Miquel. "Ruins. A visual motif of the Spanish real estate crisis / Ruïnes. Motiu visual de la crisi immobiliària espanyola". In: Comparative Cinema, Volume VII, № 12, 2019, 53-68 / 162-175.

HELL, Julia; SCHÖNLE, Andreas. Ruins of Modernity. Durham, NC: Duke University Press, 2010.

HUYSSEN, Andreas. Culturas do passado-presente: modernismo, artes visuais, políticas da memória. Rio de Janeiro: Contraponto, 2014. 2000.

LERUP, Lars. After the City. Cambridge, MA \& London, UK: The MIT Press, 
LIPOVETSKY, Gilles; SERROY, Jean. La pantalla global: cultura mediática y cine en la era hipermoderna. Barcelona: Editorial Anagrama, 2009.

LYNCH, Kevin. A imagem da cidade. São Paulo: Editora Martins Fontes, 1982.

MADERUELO, Javier (Ed.). Paisaje y arte. Huesca / Madrid: CDAN (Centro de Arte y Naturaleza) / ABADA Editores, 2007.

MÉNDEZ, Ricardo; ABAD, Luis D. \& ECHAVES, Carlos. Atlas de la crisis. Impactos socio-económicos y territorios vulnerables en España. Valencia: Tirant Humanidades, 2015.

NOLAN, Daniel P. Topics in the Philosophy of Possible Worlds. New York, NY \& London, UK: Routledge, 2002.

PORDATA. População empregada: total e por grandes setores de actividade económica. 2019. Disponível em: https://www.pordata.pt/Portugal/Popula\%C3\%A7\%C3\%A3o+empregada+total+e+por+ grandes+setores+de+actividade+econ\%C3\%B3mica-32. Acesso em: 3 de setembro de 2019.

SÁNCHEZ-RODRÍGUEZ, Julia. "EI 15-M, hacia un cambio constitucional en España a partir de los documentales 50 días de mayo (Ensayo para una revolución) (Alfonso Amador), Todos cuentan 15-M (David Serrano Bouthelier) y Excelente, revulsivo, importante (Stéphane M. Grueso)", Iberoamericana. América Latina - España - Portugal, Ano XVIII, № 69, 2018, 63-79.

SANTOS, Boaventura de Sousa. Portugal. Ensaio contra a autoflagelação. Coimbra: Almedina, 2012.

SCHULZ-DORNBURG, Julia. Ruinas modernas: una topografía de lucro. Barcelona: Àmbit Serveis Editorials, 2012.

SORLIN, Pierre. Cines europeos, sociedades europeas 1939-1990. Barcelona: Ediciones Paidós Ibérica, 1996.

VILLARINO, Ángel. "Valdeluz, de ciudad fantasma a paraíso de mileuristas y divorciados". El Confidencial, 26 de setembro de 2015. Disponível em: https://www.elconfidencial.com/espana/2015-09-26/valdeluz-de-ciudad-fantasma-aparaiso-de-mileuristas-y-divorciados 1037338/. Acesso em: 8 de setembro de 2019.

VILLARMEA ÁLVAREZ, Iván. "Blinking Spaces: Koyaanisqatsi's Cinematic City". In: SUÁREZ, Juan A.; WALTON, David (Eds.) Culture, Space and Power: Blurred Lines. Lanham, MD: Lexington Books, 2016. 33-43.

VILLARMEA ÁLVAREZ, Iván. "Rostros y espacios de la austeridad en los cines ibéricos (2007-2016)”. Iberoamericana. América Latina - España - Portugal, Ano XVIII, № $69,2018,13-36$.

VILLARMEA ÁLVAREZ, Iván. "Blinking Spaces in Contemporary Psychogeographical Documentaries". In: ROSÁRIO, Filipa; VILLARMEA ÁLVAREZ, Iván (Eds.). New Approaches to Cinematic Space. New York, NY\& London, UK: Routledge, 2019. 111-128. 
Filmografia

BLAUFUKS, Daniel. Um pouco mais pequeno que o Indiana. 2006.

BOLLAín, Icíar. El olivo. 2016.

CASTRO, David. Ilusión. 2013.

COSTA, Pedro. Cavalo Dinheiro. 2014.

DEL CASTILLO, Juan Miguel. Techo y comida. 2015.

ERICE, Víctor. Vidros partidos. 2012.

FERRERI, Marco. El pisito. 1958.

GABRIEL, Enrique. Vidas pequeñas. 2010.

GARCÍA BERLANGA, Luis. El verdugo. 1963.

GARCÍA LEÓN, Víctor. Selfie. 2017.

GATLIF, Tony. Indignados. 2012.

GOMES, Miguel. As mil e uma noites: Volume 1, O Inquieto; Volume 2, O Desolado; Volume 3, O Encantado. 2015.

GUEDES, Tiago. Tristeza e alegria na vida das girafas. 2019.

HERNANDO, Pablo. Berserker. 2015.

HESPANHA, Tiago \& LOBO, Frederico. Revolução industrial. 2014.

HOMEM, Luísa \& PINHO, Pedro. As cidades e as trocas. 2014.

KAURISMÄKI, Aki; COSTA, Pedro; ERICE, Víctor \& OLIVEIRA, Manoel de. Centro Histórico. 2012.

KEILLER, Patrick. London. 1994.

KEILLER, Patrick. Robinson in Space. 1997.

KEILLER, Patrick. Robinson in Ruins. 2010.

LEMCKE, Max. Cinco metros cuadrados. 2011.

LEÓN SIMINIANI, Elías. Mapa. 2012.

LLORCA, Pablo. País de todo a 100. 2014.

MARTINS, Marco. São Jorge. 2016.

MARZOA, Alejandro. Somos gente honrada. 2013.

MORAIS, Alberto. Los chicos del puerto. 2013. 
MOZOS, Manuel. Ruínas. 2009.

NIEVES CONDE, José Antonio. El inquilino. 1957.

PINHO, Pedro. A fábrica de nada. 2017.

REVELLI, Quentin. Bricks. 2017.

ROCHA, Paulo. Mudar de Vida. 1966.

ROSALES, Jaime. Hermosa juventud. 2014.

SANTESMASES, Miguel. Madrid above the moon. 2015.

TRUEBA, Jonás. Los ilusos. 2013.

VASCONCELOS, António-Pedro. Os gatos não têm vertigens. 2014

VERMUT, Carlos. Magical girl. 2014.

VILLARVERDE, Teresa. Colo. 2017.

WETZEL, Gereon. Casas para todos. 2013.

ZARAUZA, Alfonso. Os fenómenos. 2014. 